\title{
Prevalence of musculoskeletal disorders among perioperative nurses: a systematic review and META-analysis
}

\author{
Marco Clari', Alessandro Godono', Giacomo Garzaro ${ }^{1,2^{*}}$ (D), Gianluca Voglino', Maria Rosaria Gualano1, \\ Giuseppe Migliaretti ${ }^{1}$, Attilia Gullino ${ }^{2}$, Catalina Ciocan ${ }^{1,2}$ and Valerio Dimonte ${ }^{1,2}$
}

\begin{abstract}
Background: To evaluate the prevalence of work-related musculoskeletal disorders (WRMSDs) in perioperative nurses and to explore their association with personal characteristics.

Methods: Medline, Cumulative Index to Nursing and Allied Health Literature, Scopus, Web of Science, Cochrane Library and Joanna Briggs Institute Database were systematically searched. A meta-analysis calculating event rates, and relative 95\% Confidence Intervals (Cl) was performed for each musculoskeletal body region. The contribution of perioperative nurses' sex, age, and BMI was assessed through a meta-regression.

Results: Twenty-two studies, considering 3590 perioperative nurses, were included in the systematic review. The highest prevalence of WRMSDs was found for the lower-back (62\%; 95\% Cl 0.54-0.70), followed by knee (47\%; $95 \%$ Cl 0.36-0.59), shoulder (44\%; 95\% Cl 0.37-0.51), waist (42\%; 95\% Cl 0.31-0.53), neck (39\%; 95\% Cl 0.29-0.51), anklefeet (35\%; 95\% Cl 0.22-0.51), upper-back (34\%; 95\% Cl 0.25-0.44), hand-wrist (29\%; 95\% Cl 0.20-0.40), and elbow (18\%; 95\% Cl 0.12-0.26). Meta-regression showed that sex, age, and BMl were not significant predictors of low-back disorders $\left(p=0.69 ; R^{2}=0\right)$.

Conclusions: WRMSDs represent a high prevalence issue among perioperative nurses. Perioperative nurses, in general, are steadily exposed to both physical and temporal risk factors. Further studies should be addressed to identify specific interventions aimed at reducing the burden of WRMSDs including ergonomic education and physical rehabilitation. Our data could be used in future studies as a reference to assess the risk of WRMSDs in other health-care professionals' population.
\end{abstract}

Keywords: Musculoskeletal diseases, Operating rooms: nurses, Systematic review, Meta-analysis

\section{Background}

Musculoskeletal disorders have been considered as an impactful occupational problem among most working categories [1,2]. Work-related musculoskeletal disorders (WRMSDs) is an umbrella term for symptoms caused or worsened by work. These disorders are defined as

\footnotetext{
*Correspondence: giacomo.garzaro@unito.it

'Department of Public Health and Pediatrics, University of Torino, Via Zuretti 29, 10126 Turin, Italy

${ }^{2}$ Città della Salute e della Scienza di Torino University Hospital, Turin, Italy
}

discomfort, impairment, disability or persistent pain in the locomotor system [3].

Furthermore, WRMSDs can be classed as social and economic issues due to their impact on mental and physical health [4]. In fact, they are reported to significantly influence the quality of life, resulting in different degrees of disability, long-term diseases, work restrictions, high treatment costs, absenteeism or even transfers to other jobs [5].

(c) The Author(s). 2021 Open Access This article is licensed under a Creative Commons Attribution 4.0 International License, which permits use, sharing, adaptation, distribution and reproduction in any medium or format, as long as you give appropriate credit to the original author(s) and the source, provide a link to the Creative Commons licence, and indicate if changes were made. The images or other third party material in this article are included in the article's Creative Commons licence, unless indicated otherwise in a credit line to the material. If material is not included in the article's Creative Commons licence and your intended use is not permitted by statutory regulation or exceeds the permitted use, you will need to obtain permission directly from the copyright holder. To view a copy of this licence, visit http://creativecommons.org/licenses/by/4.0/ The Creative Commons Public Domain Dedication waiver (http://creativecommons.org/publicdomain/zero/1.0/) applies to the data made available in this article, unless otherwise stated in a credit line to the data. 
Even if the general population also experience musculoskeletal disorders, some working groups are more encumbered with those diseases. Recent studies have shown that physical factors, such as bending and twisting, manual handling, forceful movements are cardinal determinants of musculoskeletal disorders [2, 6]. From this perspective, it is no surprise that nurses, the largest professional group in health care system, have high incidence rates of musculoskeletal disorders. Nursing has been recognized as a physically demanding work and one of the jobs that continuously face high risks of WRMSDs.

Several studies have focused on the prevalence and risk factors of musculoskeletal disorders among nurses $[7,8]$ but to the best of our knowledge no meta-analyses were performed. On the other hand, few studies have been conducted internationally among perioperative nurses. In the operating room environment, the nurse's professional role involves care planning for patients in response to their needs. Working in the operating room carries its own risk of developing musculoskeletal disorders due to the exposure to additional risk factors such as prolonged standing and awkward posture during surgeries.

To our knowledge, no literature review has previously been conducted to determine the occurrence of WRMS Ds in this specific population and, accordingly, there is inconsistent evidence on possible interventions to reduce WRMDS in the operating room setting. A better understanding of the real burden of WRMSDs is crucial to highlight this health and safety issue and to promote the implementation of environmental, ergonomic and organizational interventions in these specific working populations.

Thus, the aim of this systematic review and metaanalysis is to evaluate the prevalence of work-related musculoskeletal disorders in perioperative nurses and to explore their association with personal characteristics.

\section{Methods}

Methods of the analysis and inclusion criteria were specified in advance and documented in a protocol, registered on Prospero (https://www.crd.york.ac.uk/ PROSPERO; registration number: CRD42019121982). This systematic review was reported following the Preferred Reporting Items for Systematic Reviews and Meta-Analyses (PRISMA) [9]. No ethics approval was needed as all data were obtained from publicly available sources of information.

\section{Inclusion criteria}

- Population: perioperative nurses, including operating room nurses, scrub nurses, circulating and anesthesia nurses and perioperative technicians, without age and ethnic restrictions. Since job rotation schedules are often performed in the operating room and they share the same working environment, occupational risk factors between these working categories can be considered overlapping.

- Exposure: operating room environment

- Outcomes: identify the magnitude and characteristics of WRMSDs in perioperative nurses, define the personal characteristics related to musculoskeletal disorders and evaluate the relationships between the health effects/risk factors and working conditions.

\section{Exclusion criteria}

Articles evaluating exclusively acute musculoskeletal work-related injuries and studies from non-peer reviewed journals will be excluded. Nurses working in home care were not be considered. No limit of publication date was affixed.

\section{Information sources}

Studies were identified by searching electronic databases, scanning reference lists of articles and through consultation with experts in the field. An expert librarian was involved in the search. A systematic search of Medline, Cumulative Index to Nursing and Allied Health Literature (CINAHL), Scopus, Web of Science, Cochrane Library and Joanna Briggs Institute (JBI) Database was conducted from inception to February 2019. A limited update literature search was performed on 31 June 2020. These comprehensive databases were selected because those are broad and extensive in the field of health and nursing sciences. The initial search was applied to Pubmed and then adapted to the other databases.

\section{Search strategy}

We used the following terms to search all database: perioperative nursing, musculoskeletal diseases, occupational diseases, musculoskeletal pain, cumulative trauma disorders. The complete list of the search strings for Pubmed in Online Resource 1.

\section{Study selection}

Following the search, all identified citations were gathered and uploaded on Mendeley Desktop (version 1.19.3; 2008-2018 Mendeley Ltd) and duplicates were removed. Two independent reviewers (MC, AG) screened titles and abstracts for assessment against the inclusion criteria. Afterwards, selected full texts were assessed in detail by two independent reviewers (MC, AG). Any disagreements arisen between the reviewers at any stage 
of the study selection process were solved through discussion, or with a third reviewer (GG).

\section{Data collection process and quality appraisal}

We developed a data extraction sheet (based on JBI Data Extraction Form for Review for Systematic Reviews and Research Syntheses [10], pilot-tested it on randomlyselected included studies, and refined it accordingly. One review author (AG) extracted the following data (authors, year, country, setting/context, sample size, participants-characteristics/total number, results/findings divided by musculoskeletal body regions, outcome assessed, appraisal, methods of analysis) from included studies and a second author (MC) checked the extracted data. Disagreements were resolved by discussion between the two review authors; if no agreement could be reached, a third author (GG) decided the data to be included. Five authors were contacted for further information. All answered, and one provided numerical data that was only presented graphically in the published paper.

Studies quality was appraised through the Quality Assessment Tool for Observational Cohort and CrossSectional Studies by the National Heart, Lung and Blood Institute. Two independent reviewers assessed the quality. Studies could be rated as good, fair or poor-quality basing on the reviewers assessment of risk of bias in the studies due to flaws in study design or implementation.

The level of evidence retrieved were assessed using the Grading Recommendations Assessment, Development and Evaluation (GRADE methodology. We followed GRADE guidelines of evidence about prognosis factors assessing five domains: risk of bias, imprecision, inconsistency, indirectness, and publication bias. The quality of evidence level could be rated from high to very low, depending on the level of confidence that the variation in the risk associated with the prognostic factor lies close to the estimate [11].

\section{Statistical analysis}

Period prevalence, quantified as event rates in 12 months, was the primary measure of WRMSDs occurrence. Proportion meta-analyses were performed by using the statistical software $\mathrm{R}$ version 3.6.3, using meta and metafore packages. All the studies presenting comparable outcomes were included. Event rates, and relative 95\% Confidence Intervals (CI) were calculated. The Cochran $\mathrm{Q}$ and the $\mathrm{I}^{2}$ were used to evaluate heterogeneity of studies. In order to tackle potential sources of heterogeneity between studies, the random effects model was used to combine studies if heterogeneity was shown (Cochran $\mathrm{Q} p<0.10$ and $\mathrm{I}^{2}>50 \%$ ) [12]. Moreover, to assess whether or not the publication bias was present, statistical analyses and graphs representing funnel plots were performed. Lastly, to examine the contribution of perioperative nurses' personal characteristics (sex, age, and BMI) to the heterogeneity in study findings, a metaregression was performed. $P$-values $<0.05$ were considered statistically significant.

\section{Results}

The literature research yielded a total of 2328 citations. Fourteen additional citations were added by checking the references of relevant papers and hand-searching for studies that have cited these papers. After adjusting for duplicates and screening by title, 356 articles remained. Of these, 271 studies were discarded after reviewing the abstracts. The full text of the remaining 85 citations was examined in detail. Then, 61 studies were excluded as described: 27 were not quantitative studies, 19 did not fulfill the inclusion criteria, and 15 had no pertinent data to extract. Finally, a total of 24 studies were identified for inclusion in the systematic review (Fig. 1) [13-36].

The studies were published from 2003 to 2019. They all used a cross-sectional design except from Bakola et al. [30] that used a prospective design and Keriri et al. [21] that added a nested case control study to the crosssectional design. The total sample of perioperative nurses included was 3590; most were female (77.2\%), with a mean age of 37.6 years.

Mean seniority, calculated as years working as a perioperative nurse, was 11.3 years, working on average 7.8 $\mathrm{h} /$ day. Most of the studies participants had a normal BMI (range: 22.8-26.9).

To evaluate the prevalence of WRMSDs, ten studies [13, 17, 19-21, 24, 28, 30, 32, 35] used Research-Made Questionnaire (R-M Q), nine [14, 15, 18, 22, 26, 27, 29, 31, 36] Nordic Musculoskeletal Questionnaire (NMQ), two $[29,36]$ Rapid Entire Body Assessment (REBA), one [16] Musculoskeletal Symptoms Survey (MSS), one [23] American National Standards Institute Z-365 (ANSI Z365), one [25] North American Spine SocietyQuestionnaire (NAAS-Q), one [34] Modify Oswestry Low Back Pain Disability Questionnaire (MOLBPDQ), one [33] Disabilities of the Arm, Shoulder and Hand (DASH). Moreover, two studies [26, 27] added a clinical examination to define the magnitude of WRMSDs.

Few studies evaluated the duration and intensity of symptoms, indicating a high prevalence of long-lasting symptoms especially for low-back pain [20, 21, 26, 30]. A significant association between WRMSDs and perioperative nurses' personal characteristics was reported in five studies for the female sex $[18,21,22,29,33]$ and age $[17,18,20,26,29]$, in four studies for BMI [18, 26, $28,29]$, in two studies for seniority $[26,31]$ and number of working hours $[22,33]$. Several studies described the postures and movements of PNs $[15,16,19,26]$, but the 


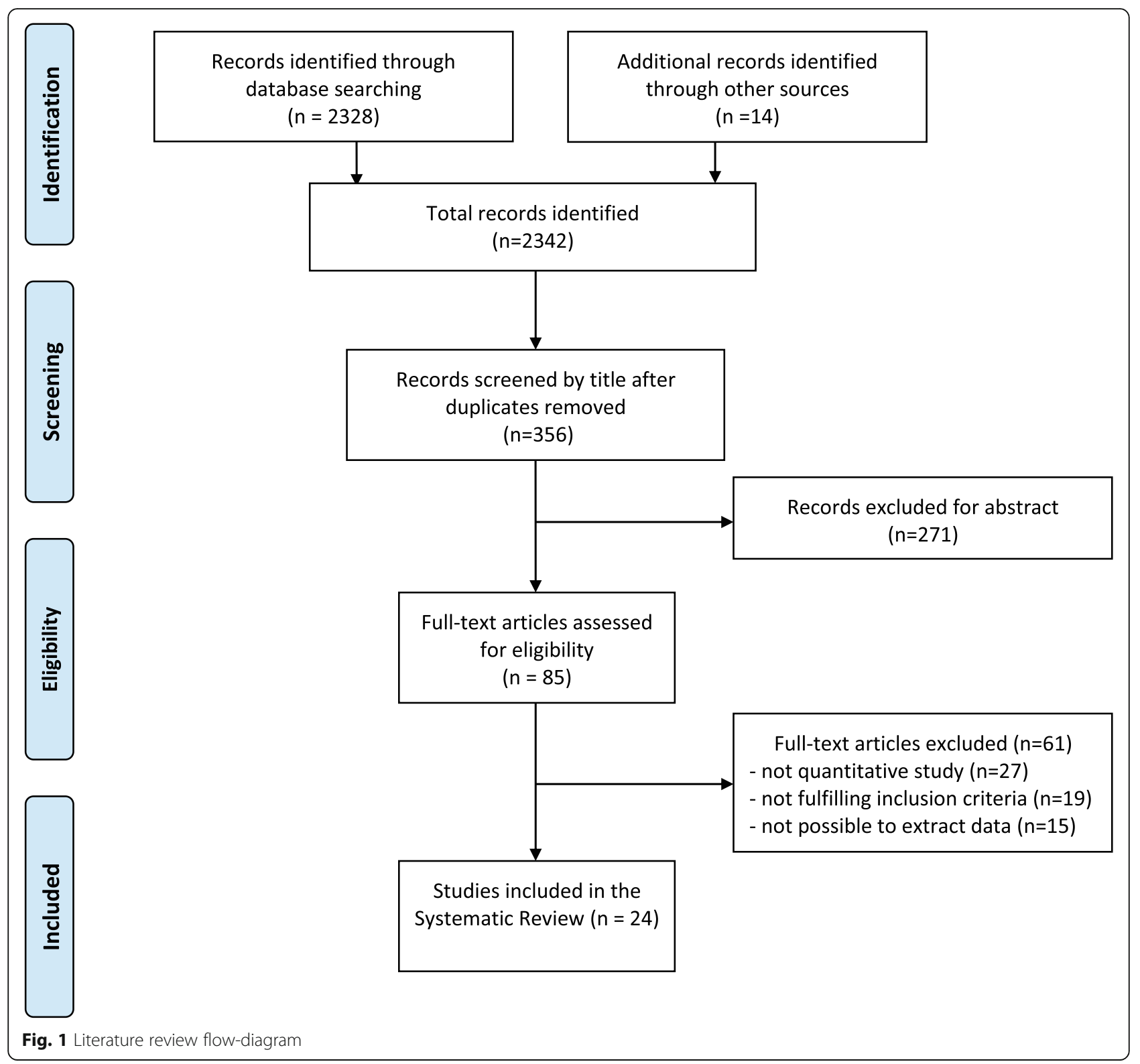

association with WRMSDs reported conflicting results $[14,18,21,28,30,32,34,36]$.

All the studies had a fair quality rating. The complete critical appraisal is reported in Online Resource 2.

A detailed summary of the characteristics of the included studies is reported in Table 1.

\section{Meta-analysis}

Table 2 shows the 12 months prevalence of WRMSDs in the identified 9 musculoskeletal body regions.

Lower back issues were the most present WRMSD with a $62 \%$ prevalence from 19 studies [14-21, 24-31, 34-36]. The knee region had a WRMSDs prevalence of $47 \%$, followed by the shoulder (44\%), the waist (42\%) regions. The other regions had the following prevalence: neck (39\%), upper-back (34\%), ankle-feet (35\%), handwrist (29\%), and elbow (18\%) (Table 2). The forest plots illustrate the meta-analyses of the nine musculoskeletal body regions, grouped into upper-limbs (Fig. 2), back (Fig. 3), and lower-limbs (Fig. 4).

There was evidence of significant heterogeneity $\left(\mathrm{I}^{2}>\right.$ $50 \%)$ in all the meta-analyses performed. The funnel plots for all the meta-analyses were scattered and asymmetrical, representing a possible presence of reporting bias.

Due to the limited number of studies considering perioperative nurses characteristics, it was possible to perform a meta-regression for lower back region only. This meta-regression showed that sex, age, and BMI were not significant predictors of low back disorders $(p=0.69$; $\left.R^{2}=0\right)$. 
Table 1 Characteristics of the included studies

\begin{tabular}{|c|c|c|c|c|c|c|}
\hline Author/Year & Country & Study design & Sample size/sex/age & BMI & $\begin{array}{l}\text { Data } \\
\text { assesment }\end{array}$ & $\begin{array}{l}\text { Critical } \\
\text { appraisal }\end{array}$ \\
\hline $\begin{array}{l}\text { Ruzafa-Martinez et al. } \\
\text { (2003) [13] }\end{array}$ & Spain & cross-sectional & 24 PNs: $22 \mathrm{~F} ; 2 \mathrm{M}$ & a & R-M Q & fair \\
\hline Bos et al. (2007) [14] & Netherlands & cross-sectional & 381 PNs: 324 F; 57 M. Age: $40 \pm 10$ & $24 \pm 4$ & NMQ & fair \\
\hline $\begin{array}{l}\text { Meijsen et al. (2007) } \\
\text { [15] }\end{array}$ & Netherlands & cross-sectional & 463 PNs: 394 F; 69 M. Age: $36 \pm 10.3$ & a & NMQ & fair \\
\hline $\begin{array}{l}\text { Sheikhzadeh et al. } \\
\text { (2009) [16] }\end{array}$ & US & cross-sectional & 32 PNs. Age: $43.9 \pm 9.1$ & a & MSS & fair \\
\hline $\begin{array}{l}\text { Choobineh et al. } \\
\text { (2010) [18] }\end{array}$ & Iran & cross-sectional & 375 PNs: 249 F; 126 M. Age: $31.5 \pm 8.5$ & $\begin{array}{l}22.8 \pm \\
3.3\end{array}$ & NMQ & fair \\
\hline $\begin{array}{l}\text { Moscato et al. (2010) } \\
{[17]}\end{array}$ & Italy & cross-sectional & 185 PNs: 73 F; 112 M. Age: $36.1 \pm 7.1$ & $\begin{array}{l}M \\
22.6 \pm \\
3.2 \\
F \\
25.5 \pm \\
3.7\end{array}$ & R-M Q & fair \\
\hline $\begin{array}{l}\text { Aljeesh et al. (2011) } \\
\text { [19] }\end{array}$ & Palestine & cross-sectional & 143 PNs: 33 F, 110 M. Age: $33.7 \pm 9.59$ & $\begin{array}{l}26.6 \pm \\
4.5\end{array}$ & R-M Q & fair \\
\hline $\begin{array}{l}\text { Hinmikaiye et al. (2012) } \\
\text { [20] }\end{array}$ & Nigeria & cross-sectional & 80 PNs: 56 F; 24 M. & a & R-M Q & fair \\
\hline $\begin{array}{l}\text { Simonsen et al. (2012) } \\
\text { [32] }\end{array}$ & Sweden & cross-sectional & $99 \mathrm{PNs}$ & a & R-M Q & fair \\
\hline Keriri et al. (2013) [21] & $\begin{array}{l}\text { Saudi } \\
\text { Arabia }\end{array}$ & $\begin{array}{l}\text { cross-sectional + nested } \\
\text { case control }\end{array}$ & $\begin{array}{l}126 \text { PNs (94 ORNs, } 32 \text { Technicians): } 99 \text { F; } 27 \\
\text { M. Age: } 34.0 \pm 8.0\end{array}$ & $\begin{array}{l}24.9 \pm \\
4.5\end{array}$ & R-M Q & fair \\
\hline $\begin{array}{l}\text { Arsalani et al. (2014) } \\
\text { [22] }\end{array}$ & Iran & cross-sectional & 117 PNs & a & NMQ & fair \\
\hline Ryu et al. (2014) [23] & $\begin{array}{l}\text { South } \\
\text { Korea }\end{array}$ & cross-sectional & 35 PNs: $35 \mathrm{~F}$ & a & ANSI Z-365 & fair \\
\hline Nützi et al. (2015) [25] & Switzerland & cross-sectional & 116 PNs: 97 F; 19 M. Age: $3.9 \pm 11.9$ & a & NAAS-Q & fair \\
\hline $\begin{array}{l}\text { Uğurlu et al. (2015) } \\
\text { [24] }\end{array}$ & Turkey & cross-sectional & 74 PNs: 46 F; 28 M. Age: $29.3 \pm 6.7$ & a & R-M Q & fair \\
\hline $\begin{array}{l}\text { Arvidsson et al. (2016) } \\
\text { [27] }\end{array}$ & Sweden & cross-sectional & 305 PNs: 305 F. Age: $47 \pm 10$ & $24 \pm 4$ & $\mathrm{CE}+\mathrm{NMQ}$ & fair \\
\hline Asadi et al. (2016) [28] & Iran & cross-sectional & 45 PNs & a & R-M Q & fair \\
\hline El Ata et al. (2016) [26] & Egypt & cross-sectional & 184 PNs: 155 F; 29 M. Age: $20-50$ ys & $<30$ & $\mathrm{CE}+\mathrm{NMQ}$ & fair \\
\hline $\begin{array}{l}\text { Homaid et al. (2016) } \\
\text { [35] }\end{array}$ & $\begin{array}{l}\text { Saudi } \\
\text { Arabia }\end{array}$ & cross-sectional & 41 PNs (34 ORN, 7 Technicians) & a & R-M Q & $?$ \\
\hline Bakola et al. (2017) [30] & Greece & prospective & 44 PNs: 35 F; 9 M. Age: $42.7 \pm 5.5$ & $\begin{array}{l}24.7 \pm \\
4.3\end{array}$ & R-M Q & fair \\
\hline $\begin{array}{l}\text { Mahmoudifar et al. } \\
\text { (2017) [29] }\end{array}$ & Iran & cross-sectional & $50 \mathrm{PNs}$ & a & $\begin{array}{l}\text { NMQ }+ \\
\text { REBA }\end{array}$ & fair \\
\hline $\begin{array}{l}\text { Nasiri-Ziba et al. (2017) } \\
\text { [31] }\end{array}$ & Iran & cross-sectional & 133 PNs: 103 F; 30 M. Age: $29.1 \pm 6.8$ & $\begin{array}{l}23.1 \pm \\
2.7\end{array}$ & NMQ & fair \\
\hline $\begin{array}{l}\text { Jeyakumar et al. (2018) } \\
\text { [34] }\end{array}$ & US & cross-sectional & 250 PNs: 220 F; $30 \mathrm{M}$ & 24.5 & MOLBPDQ & fair \\
\hline $\begin{array}{l}\text { Asghari et al. (2019) } \\
\text { [36] }\end{array}$ & Iran & cross-sectional & 144 PNss: 115 F; 29 M. Age: $34.6 \pm 6.6$ & $\begin{array}{l}24.4 \pm \\
2.9\end{array}$ & $\begin{array}{l}\mathrm{NMQ}+ \\
\mathrm{REBA}\end{array}$ & $?$ \\
\hline Clari et al. (2019) [33] & Italy & cross-sectional & 144 PNs: $114 \mathrm{~F} ; 30 \mathrm{M}$ & a & DASH & fair \\
\hline
\end{tabular}

\footnotetext{
adata not available
}

$B M I$ Body Mass Index, M Male, F Female, PNs perioperative nurses, R-M Q Research-Made Questionnaire, NMQ Nordic Musculoskeletal Questionnaire, MSS Musculoskeletal symptom Survey, ANSI Z-365 American National Standards Institute Z-365, NAAS-Q North American Spine Society-Questionnaire, CE Clinical Examination, REBA Rapid Entire Body Assessment, MOLBPDQ Modify Oswestry Low Back Pain Disability Questionnaire, DASH Disabilities of the Arm, Shoulder and Hand 
Table 2 Twelve-month prevalence of WRMSDs in musculoskeletal body regions, certainty assessment and level of evidence

\begin{tabular}{llllllll}
\hline \multirow{2}{*}{$\begin{array}{l}\text { No of } \\
\text { studies }\end{array}$} & Certainty assessment & & & Effect & Certainty \\
\cline { 2 - 3 } & Study design & $\begin{array}{l}\text { Risk of } \\
\text { bias }\end{array}$ & Inconsistency & Indirectness & Imprecision Other considerations & $\begin{array}{l}\text { No of } \\
\text { individuals }\end{array}$ & $\begin{array}{l}\text { Event } \\
\text { rate }(95 \% \mathrm{Cl})\end{array}$
\end{tabular}

Neck (follow up: 12 months; assessed with: Prevalence)

\begin{tabular}{|c|c|c|c|c|c|c|c|c|c|}
\hline 11 & $\begin{array}{l}\text { observational } \\
\text { studies }\end{array}$ & $\begin{array}{l}\text { not } \\
\text { serious }\end{array}$ & serious $^{b}$ & not serious $^{c}$ & serious $^{d}$ & $\begin{array}{l}\text { publication bias strongly } \\
\text { suspected }{ }^{\text {e }}\end{array}$ & 1900 & $39 \%(29-51)$ & $\begin{array}{l}\text { ๑OOOVERY } \\
\text { LOW }\end{array}$ \\
\hline \multicolumn{10}{|c|}{ Shoulder (follow up: 12 months; assessed with: Prevalence) } \\
\hline & $\begin{array}{l}\text { observational } \\
\text { studies }\end{array}$ & $\begin{array}{l}\text { not } \\
\text { serious }^{\text {a }}\end{array}$ & serious $^{b}$ & not serious ${ }^{c}$ & not serious ${ }^{f}$ & $\begin{array}{l}\text { publication bias strongly } \\
\text { suspected }{ }^{\text {e }}\end{array}$ & 1518 & $44 \%(37-51)$ & $\oplus \oplus O O L O W$ \\
\hline
\end{tabular}

Elbow (follow up: 12 months; assessed with: Prevalence)

$8 \quad$ observational not serious $^{b} \quad$ not serious $^{c}$ not serious ${ }^{\mathrm{f}}$ publication bias strongly 1102

18\% (12-26) $\oplus \oplus$ OLOW

Hand-wrist (follow up: 12 months; assessed with: Prevalence)

\begin{tabular}{|c|c|c|c|c|c|c|c|c|c|}
\hline 10 & $\begin{array}{l}\text { observational } \\
\text { studies }\end{array}$ & $\begin{array}{l}\text { not } \\
\text { serious }^{a}\end{array}$ & serious $^{b}$ & not serious ${ }^{c}$ & not serious ${ }^{f}$ & $\begin{array}{l}\text { publication bias strongly } \\
\text { suspected }^{\text {e }}\end{array}$ & 1518 & $29 \%(20-40)$ & $\oplus \oplus \circ O L O W$ \\
\hline \multicolumn{10}{|c|}{ Upper-back (follow up: 12 months; assessed with: Prevalence) } \\
\hline 8 & $\begin{array}{l}\text { observational } \\
\text { studies }\end{array}$ & $\begin{array}{l}\text { not } \\
\text { serious }^{a}\end{array}$ & serious $^{b}$ & not serious ${ }^{c}$ & not serious ${ }^{f}$ & $\begin{array}{l}\text { publication bias strongly } \\
\text { suspected }\end{array}$ & 994 & $34 \%(25-44)$ & $\oplus \oplus \circ O L O W$ \\
\hline \multicolumn{10}{|c|}{ Lower-back (follow up: 12 months; assessed with: Prevalence) } \\
\hline 19 & $\begin{array}{l}\text { observational } \\
\text { studies }\end{array}$ & $\begin{array}{l}\text { not } \\
\text { serious }^{a}\end{array}$ & serious $^{b}$ & not serious $^{c}$ & not serious $^{f}$ & $\begin{array}{l}\text { publication bias strongly } \\
\text { suspected }{ }^{~}\end{array}$ & 3139 & $62 \%(54-70)$ & $\oplus \oplus \circ O \mathrm{LOW}$ \\
\hline \multicolumn{10}{|c|}{ Waist (follow up: 12 months; assessed with: Prevalence) } \\
\hline 7 & $\begin{array}{l}\text { observational } \\
\text { studies }\end{array}$ & $\begin{array}{l}\text { not } \\
\text { serious }^{a}\end{array}$ & serious $^{b}$ & not serious $^{c}$ & ${ }_{d}^{\text {not serious }}$ & $\begin{array}{l}\text { publication bias strongly } \\
\text { suspected }{ }^{\text {e }}\end{array}$ & 1020 & $42 \%(31-53)$ & $\oplus \oplus \circ O L O W$ \\
\hline \multicolumn{10}{|c|}{ Knee (follow up: 12 months; assessed with: Prevalence) } \\
\hline 8 & $\begin{array}{l}\text { observational } \\
\text { studies }\end{array}$ & $\begin{array}{l}\text { not } \\
\text { serious }^{a}\end{array}$ & serious $^{b}$ & not serious ${ }^{c}$ & not serious ${ }^{f}$ & $\begin{array}{l}\text { publication bias strongly } \\
\text { suspected }{ }^{\text {e }}\end{array}$ & 1070 & $47 \%(36-59)$ & $\oplus \oplus \circ O L O W$ \\
\hline \multicolumn{10}{|c|}{ Ankle-feet (follow up: 12 months; assessed with: Prevalence) } \\
\hline 9 & $\begin{array}{l}\text { observational } \\
\text { studies }\end{array}$ & $\begin{array}{l}\text { not } \\
\text { serious }\end{array}$ & serious $^{b}$ & not serious ${ }^{c}$ & serious $^{d}$ & $\begin{array}{l}\text { publication bias strongly } \\
\text { suspected }^{\text {e }}\end{array}$ & 1375 & $35(22-51)$ & $\begin{array}{l}\text { ĐOOOVERY } \\
\text { LOW }\end{array}$ \\
\hline
\end{tabular}

${ }^{\mathrm{a} S t u d i e s ~ h a v e ~ a ~ f a i r ~ q u a l i t y ~ r a t i n g ~}$

${ }^{b}{ }_{12}>50 \%$

'The studied population correspond to the population in study

${ }^{d}$ The effect on clinical action could differ depending on the $95 \% \mathrm{Cl}$

${ }^{\mathrm{e}}$ Funnel and doi plot reporting major asymmetry

${ }^{\mathrm{f}}$ The effect on clinical action not differ depending on the $95 \% \mathrm{Cl}$

\section{Level of evidence}

The overall quality of evidence was low for all the body regions, but for the neck and ankle-feet regions the quality of evidence was very low. There is limited certainty that the variation in risk is associated with the perioperative nurse job. The level of evidence for observational studies was downgraded due to the high heterogeneity of the pooled meta-analyses and the suspected publication bias highlighted by the major asymmetry of the funnel and doi plots. The estimates with low quality of evidence were downgraded due to the large 95\% CI.

\section{Discussion}

This systematic review and meta-analysis evaluated the prevalence of WRMSDs in perioperative nurses and their association with personal characteristics. Musculoskeletal disorders are one of the highest contributors to global disability [37]. Recently, the World Health Organization estimated that between 20 and 33\% of general population live with a painful musculoskeletal condition [38]. In particular, WRMSDs remain the most common work-related health problem in the European Union and workers in all sectors and occupations can be affected. Of all workers in the European Union with a work-related health problem, $60 \%$ identify musculoskeletal disorders as their most serious issue [6].

Specifically, health-care professionals might be at high risk of incurring in musculoskeletal disorders [39]. Our results are in line with literature for other health-care professionals. According to a recent systematic review, nearly three out of four nurses employed in a hospital suffered from pain or discomfort in at least one of any of the musculoskeletal body regions during the past 12 months of work [5]. In this review, the three 
a: $\underline{\text { Neck }}$

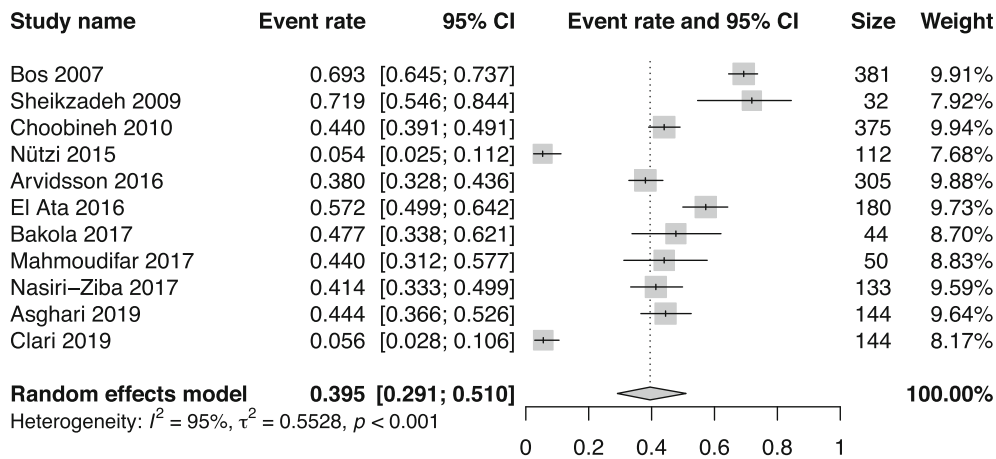

b: $\underline{\text { Shoulder }}$

\begin{tabular}{|c|c|c|c|c|}
\hline Study name & Event rate & Event rate and $95 \% \mathrm{Cl}$ & Size & Weight \\
\hline Sheikzadeh 2009 & $0.750[0.579 ; 0.867]$ & + & 32 & $6.36 \%$ \\
\hline Choobineh 2010 & $0.517[0.467 ; 0.567]$ & + & 375 & $11.96 \%$ \\
\hline Nützi 2015 & $0.384[0.299 ; 0.476]$ & -1 & 112 & $10.37 \%$ \\
\hline Arvidsson 2016 & $0.441[0.386 ; 0.497]$ & + & 304 & $11.78 \%$ \\
\hline El Ata 2016 & $0.611[0.538 ; 0.679]$ & $\rightarrow$ & 180 & $11.16 \%$ \\
\hline Bakola 2017 & $0.455[0.317 ; 0.599]$ & 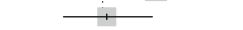 & 44 & 8.20 \\
\hline Mahmoudifar 2017 & $0.300[0.191 ; 0.438]$ & $\longrightarrow$ & 50 & 8.09 \\
\hline Nasiri-Ziba 2017 & $0.346[0.270 ; 0.430]$ & $\longrightarrow$ & 133 & 10.60 \\
\hline Asghari 2019 & $0.333[0.262 ; 0.414]$ & 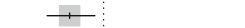 & 144 & 10.71 \\
\hline Clari 2019 & $0.361[0.287 ; 0.442]$ & 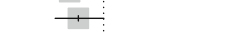 & 144 & 10.77 \\
\hline Random eff & $0.441[0.373 ; 0.512]$ & $\infty$ & \multirow{2}{*}{\multicolumn{2}{|c|}{$100.00 \%$}} \\
\hline \multicolumn{2}{|c|}{ Heterogeneity: $I^{2}=85 \%, \tau^{2}=0.1663, p<0.001$} & $T$ & & \\
\hline
\end{tabular}

c: Elbow

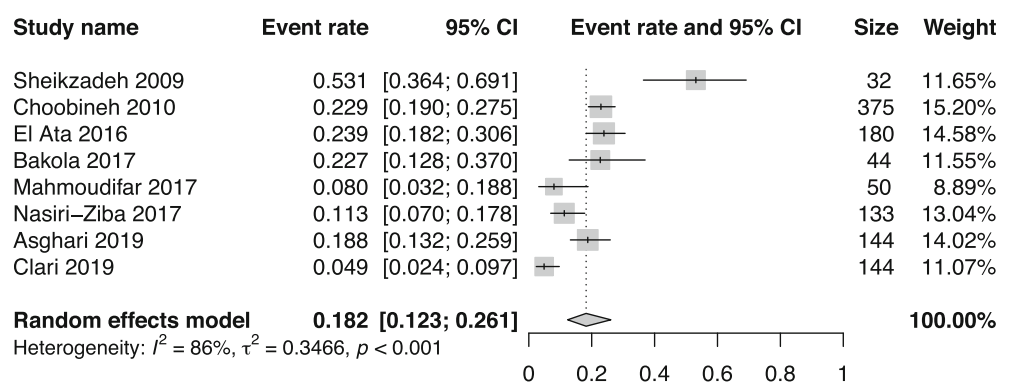

\section{d: Hand-wrist}

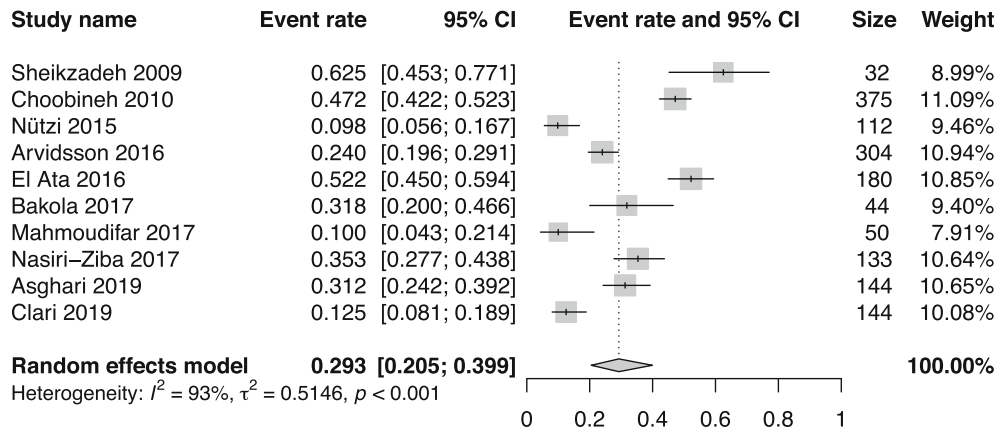

Fig. 2 Meta-analysis of the prevalence of upper-limbs work-related musculoskeletal disorders for the neck (a), shoulder (b), elbow (c), and handwrist (d) musculoskeletal body regions 


\section{a: Upper-back}

\begin{tabular}{|c|c|c|c|c|c|}
\hline Study name & Event rate & $95 \% \mathrm{Cl}$ & Event rate and $95 \% \mathrm{Cl}$ & Size & Weight \\
\hline Sheikzadeh 2009 & 0.438 & {$[0.282 ; 0.607]$} & + & 32 & $10.74 \%$ \\
\hline Choobineh 2010 & 0.547 & {$[0.496 ; 0.596]$} & + & 375 & $14.52 \%$ \\
\hline Hinmikaiye 2012 & 0.351 & {$[0.240 ; 0.481]$} & -1 & 57 & $12.09 \%$ \\
\hline Nützi 2015 & 0.205 & {$[0.141 ; 0.289]$} & 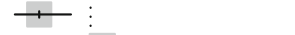 & 112 & $12.81 \%$ \\
\hline El Ata 2016 & 0.372 & {$[0.305 ; 0.445]$} & 4 & 180 & $13.97 \%$ \\
\hline Bakola 2017 & 0.250 & {$[0.146 ; 0.394]$} & $\longrightarrow$ & 44 & $10.88 \%$ \\
\hline Mahmoudifar 2017 & 0.260 & {$[0.159 ; 0.396]$} & $\hookrightarrow$ & 50 & $11.32 \%$ \\
\hline Asghari 2019 & 0.326 & {$[0.255 ; 0.407]$} & $\longrightarrow$ & 144 & $13.66 \%$ \\
\hline Random effects model & 0.341 & {$[0.252 ; 0.443]$} & 2 & & $100.00 \%$ \\
\hline \multirow{2}{*}{ Heterogeneity: $I^{2}=89 \%, \tau$} & $.3196, p$ & $<0.001$ & T & 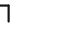 & \\
\hline & & 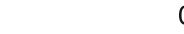 & 0.2 & 1 & \\
\hline
\end{tabular}

\section{b: Lower-back}

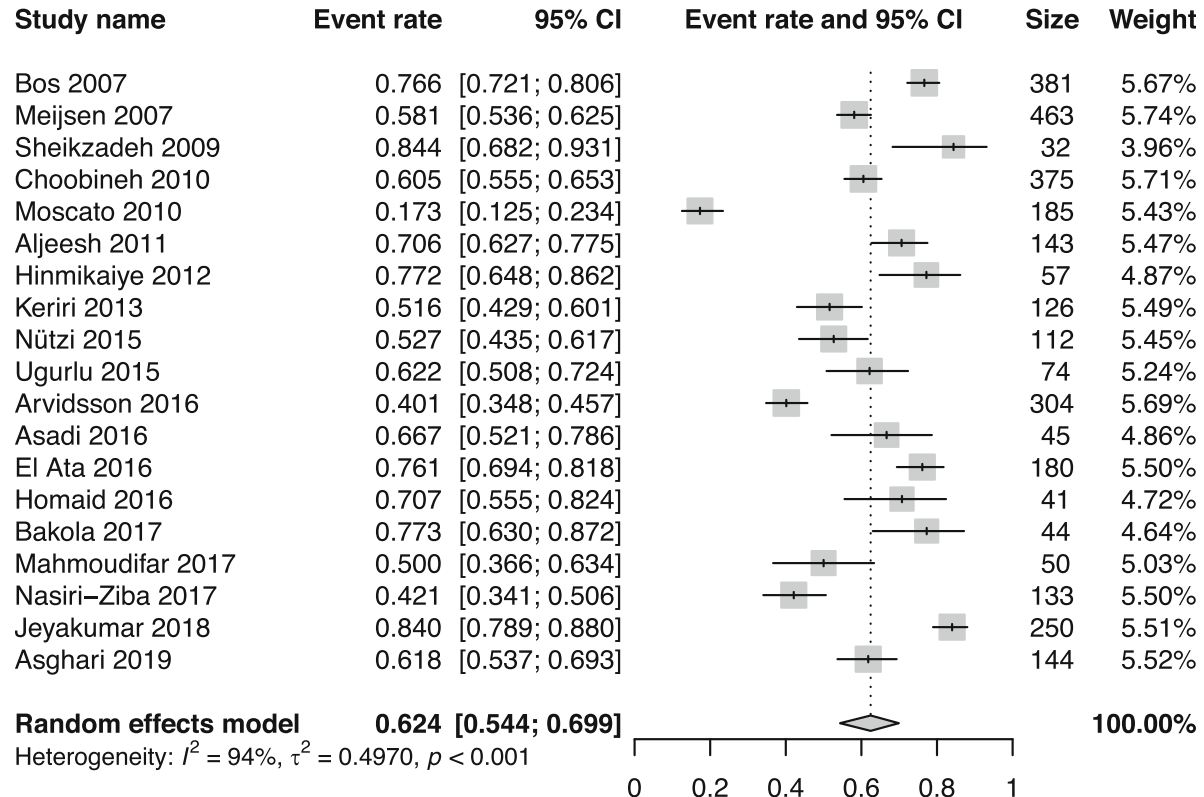

Fig. 3 Meta-analysis of the prevalence of back work-related musculoskeletal disorders for the upper-back (a), and lower-back (b) musculoskeletal body regions

musculoskeletal body regions mostly affected were: lower back (65.3\%), knees (56.2\%) and neck (49.8\%) [5]. Also, results from a cross-sectional study conducted on nursing aides working in nursing homes showed that $87.4 \%$ of the study population experienced musculoskeletal disorders in the previous year (lower back $41.4 \%$, shoulders 53\%, knees 37.5\%) [40]. Furthermore, a high prevalence of WRMSD has been also observed in X-ray technologists with an overall 12-months prevalence of low back pain of $75.1 \%$ and a $64.2 \%$ of the neckshoulder segment [14]. In particular, the operating room setting appears to be at high risk of causing WRMSDs. Epstein et al. reported, among a large sample of surgeons and interventionalists, an overall 12-month prevalence of neck pain of $60 \%$, of shoulder pain of $52 \%$, of back pain of $49 \%$ and of upper extremities of $35 \%$ [41].

The highest prevalence of musculoskeletal disorders in the working population is attributable to disorders at the back region. Consistently, the general population shows a lower back pain life-time prevalence between 51 to $90 \%$ [42]. Just for the low back region, it has been estimated that approximately $\$ 50$ billion per year is spent in the United States [43]. Nursing has been identified amongst the top professions at risk of lower back pain [44]. Our results showed that more than $60 \%$ of perioperative nurses suffered from work-related lower back pain, and this is particularly relevant if we consider that 
a: Waist

\begin{tabular}{|c|c|c|c|c|}
\hline Study name & Event rate & Event rate and $95 \% \mathrm{Cl}$ & Size & Weight \\
\hline Sheikzadeh 2009 & $0.531[0.364 ; 0.691]$ & + & 32 & $12.04 \%$ \\
\hline Choobineh 2010 & $0.307[0.262 ; 0.355]$ & + & 375 & $15.76 \%$ \\
\hline Nützi 2015 & $0.527[0.435 ; 0.617]$ & -1 & 112 & $14.82 \%$ \\
\hline El Ata 2016 & $0.467[0.395 ; 0.539]$ & 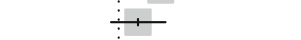 & 180 & $15.35 \%$ \\
\hline Bakola 2017 & $0.273[0.163 ; 0.418]$ & $\longrightarrow$ & 44 & $12.32 \%$ \\
\hline Nasiri-Ziba 2017 & $0.617[0.532 ; 0.695]$ & $\longrightarrow$ & 133 & $14.98 \%$ \\
\hline Asghari 2019 & $0.236[0.174 ; 0.312]$ & + & 144 & $14.72 \%$ \\
\hline Random effects model & $0.416[0.308 ; 0.532]$ & & & $100.00 \%$ \\
\hline \multirow{2}{*}{\multicolumn{2}{|c|}{ Heterogeneity: $I^{2}=91 \%, \tau^{2}=0.3530, p<0.001$}} & $T$ & & \\
\hline & & 0.2 & 1 & \\
\hline
\end{tabular}

\section{b: $\underline{\text { Knee }}$}

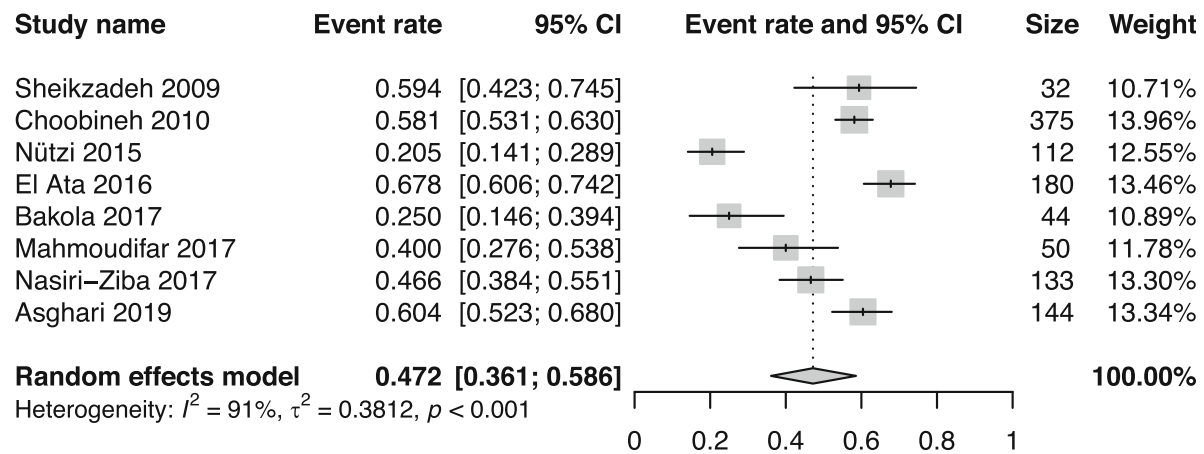

\section{c: Ankle-feet}

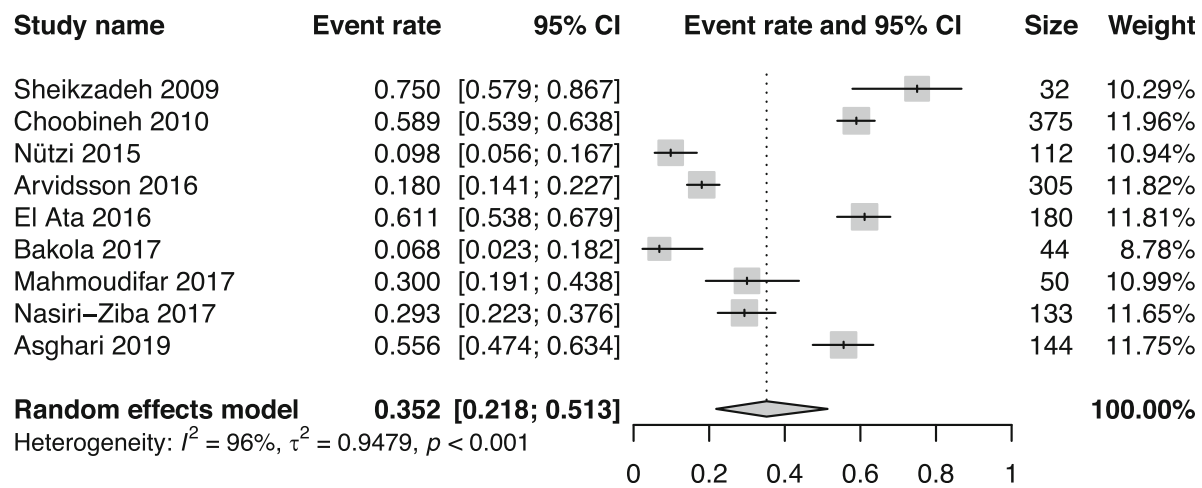

Fig. 4 Meta-analysis of the prevalence of lower-limbs work-related musculoskeletal disorders for the waist (a), knee (b), and ankle-feet (c) musculoskeletal body regions

perioperative nurses, in general, could be highly exposed to both physical and temporal risk factors, such as low temperature, highly repetitive tasks at high force, and frequent use of vibrating instruments. Furthermore, perioperative health-care professionals have to maintain static postures during surgical procedures for an extended time [45]. The impossibility of switching body positions is a relevant contributor to fatigue and health problems related to the lower back region [46].

Several personal characteristics could be related to WRMSDs. Among these characteristics, the female sex seems to be associated with a greater risk of lower-back problems both in nurses $[47,48]$ and in the population of operating room nurses [18, 21, 22, 25, 29, 33]. Despite this, in our review female sex was not a significant 
predictor of low back disorders. Traditionally, sex has not been considered a predictor of WRMSDs, but a confounding or modifying factor due to the mixed exposure to work and extra-work activities. However, according to some recent studies, employed women seem to have an increased risk of WRMSDs, in particular in the upperbody musculoskeletal region. The most likely explanation of the increased risk of WRMSDs in female workers might be the differences in somatic, hormonal, and psychological aspects. Furthermore, women are more prone to WRMSDs in cold working environments [49] and there can be differences in repetitive procedures used between males and females [50]. Moreover, women are usually more in charge of the domestic work, and this further burden could increase musculoskeletal issues [51]. The combined work-home exposure to musculoskeletal demands could also reduce the opportunity for recovery time, and for strengthening body muscles with a higher risks of overweight consequences [52]. Lastly, future studies need to understand the links between biological and psychosocial aspects addressing not only the somatic and functional differences between male and female sex but also accounting for the similarities in male and female behaviors [53].

Percentages of overweight and obesity are high among employed adults with rising rates over the past few decades [54]. Several studies have linked a high BMI with musculoskeletal disorders and the repetitive work [55, 56]. This statement could have been true especially for our population, particularly those exposed to prolonged repetitive tasks in awkward postures. Surprisingly, although some studies $[18,26,28,29]$ considered in our meta-analysis reported an association between an increased BMI and WRMDs, the meta-regression results did not confirm this assumption. This might be due to a younger age of perioperative nurses compared to other nursing roles [57], and that the BMI alone could not represent a reliable predictor.

It is also known that musculoskeletal disorders related to work are a major cause of disability in older workers [58]. In this regard, more than one third of the nursing workforce in the United States is between the ages of 50 and 64 [59]. In our sample, the mean age was lower with an average age of 36.7 years. This could be explained in part by the fact that perioperative nurses usually begin their career right after the graduation, and that through the years they usually change their position from the operation room to outpatients' settings, usually with minor physical burden. This assumption could explain the absence of association in the meta-regression. Only a few studies $[17,18,20,28$, 29] have shown a correlation between age and WRMSDs.

To date, scientific literature regarding possible interventions to reduce WRMDS in the operating room setting is poor. A multidisciplinary approach that takes into consideration environmental, ergonomic, and organizational factors would be recommended to address this issue. In this regard, particular attention should be given to the evaluation of repetitive motions and prolonged restricted posture, handling heavy weight, forceful gripping, low temperatures, the use of vibrating instruments and to the frequency, intensity, and duration of each task performed at work. Possible ergonomic interventions to minimize risks and reduce the incidence of work-related lower back disorders should include: propping alternating feet on foot stools, using anti-fatigue mats, using sit/stand stools, limiting standing times, wearing appropriate footwear, and implementing postural exercises such as regular contraction and relaxation of muscles during the surgical procedures [60]. Moreover, perioperative nurses could benefit from ergonomic education and physical rehabilitation, if needed. Also, organizational strategies can be adopted to allow a more effective management of human resources, especially when assigning workers to specific jobs or tasks such as job mechanization, job rotation, job enlargement, and the design of a safe work environment [61]. Due to the multifaceted nature of WRMDSs and the complexity of the perioperative nurse job, the proposed preventive strategies could be most beneficial if combined. For these reasons, future efforts should be directed to assess the real effectiveness of preventive measures and to standardize their implementation.

This review has some potential limitations. Data from the articles included in the meta-analysis may not represent the general population heterogeneously, in fact about a quarter of the studies were conducted in Iran, limiting the generalizability due to contextual factors. The high heterogeneity in the meta-analyses could be related to several elements. Firstly, the clinical settings and the role and responsibilities of perioperative nurses could differ between countries. Furthermore, it was not possible to stratify by surgical specialties due to the lack of data and even within the same surgical specialty, the surgical procedures could differ for the adoption of specific surgical techniques. Moreover, the diagnosis of WRMSDs is quite difficult itself, including both clinicaldiagnostic heterogeneity and subjective psychosocial components. In this regard, most included studies evaluate the prevalence of WRMSDs through self-reported measures without imaging support nor clinical examination. Lastly, the lack of data from included studies could have limited the results of the meta-regression. Despite these limitations this is the first systematic review conducted on this topic providing a meta-analysis.

\section{Conclusions}

WRMSDs represent a high prevalence issue among perioperative nurses. The musculoskeletal body regions 
mostly affected were lower back, shoulder, waist, and knee. Age, sex and BMI seem not to be related to WRMSDs prevalence. Environmental, ergonomic and organizational factors should be implemented trying to reduce the burden of WRMSDs in perioperative nurses. Our data could be used in future studies as a reference to assess the risk of WRMSDs in other health-care professionals' population.

\section{Supplementary Information}

The online version contains supplementary material available at https://doi. org/10.1186/s12891-021-04057-3.

Additional file 1. Search strings for Pubmed.

Additional file 2. Quality Assessment.

\section{Abbreviations}

WRMSDs: Work-related musculoskeletal disorders; Cl: Confidence Intervals; PRISMA: Preferred Reporting Items for Systematic Reviews and MetaAnalyses; CINAHL: Cumulative Index to Nursing and Allied Health Literature; BMI: Body Mass Index; PNs: Perioperative nurses; R-M Q: Research-Made Questionnaire; NMQ: Nordic Musculoskeletal Questionnaire; MSS: Musculoskeletal symptom Survey; ANSI Z-365: American National Standards Institute Z-365; NAAS-Q: North American Spine SocietyQuestionnaire; CE: Clinical Examination; REBA: Rapid Entire Body Assessment; MOLBPDQ: Modify Oswestry Low Back Pain Disability Questionnaire; DASH: Disabilities of the Arm Shoulder and Hand

\section{Authors' contributions}

MC, AG and GG designed the work and made substantial contribution to its conception and development. GV, GM and MRG performed the statistical analyses. MC, AG and GV drafted the paper. AG, CC and VD critically revised the manuscript and helped to realize the final draft. The author(s) read and approved the final manuscript.

\section{Funding}

This study did not received any funding.

\section{Availability of data and materials}

The majority of data generated or analysed during this study are included in this published article [and its supplementary information files]. Further datasets used and/or analysed during the current study are available from the corresponding author on reasonable request.

\section{Ethics approval and consent to participate}

Not applicable.

\section{Consent for publication}

Not applicable.

\section{Competing interests}

All authors declare that they have no conflict of interest.

Received: 7 September 2020 Accepted: 8 February 2021 Published online: 26 February 2021

\section{References}

1. Garzaro G, Decillis E, Donato F, Patrucco M, Pira E. Evolution of the concept OS\&H from the second post-war to today: from prescriptive system to assessment and management of risks in system quality -the extended model in collaboration with large facilities. Evolution of multidisciplinary culture of safety. GEAM. 2018;154(2):16-20.

2. Parno A, Sayehmiri K, Parno M, Khandan M, Poursadeghiyan M, Maghsoudipour M, et al. The prevalence of occupational musculoskeletal disorders in Iran: a meta-analysis study. Work. 2017;58(2):203-14.
3. Martinelli S, Artioli G, Vinceti M, Bergomi M, Bussolanti N, Camellini R, et al. Low back pain risk in nurses and its prevention. Prof Inferm. 2004;57(4):23842.

4. Morse TF, Dillon C, Warren N, Levenstein C, Warren A. The economic and social consequences of work-related musculoskeletal disorders: the Connecticut upper-extremity surveillance project (CUSP). Int J Occup Environ Health. 1998;4(4):209-16.

5. Soylar P, Ozer A. Evaluation of the prevalence of musculoskeletal disorders in nurses: a systematic review. Med Sci Int Med J. 2018;7(3):479-8.

6. European Agency for Safety and Health at Work. Work-related musculoskeletal disorders : prevalence, costs and demographics in the EU. Luxembourg: Publications Office of the European Union; 2019.

7. Davis KG, Kotowski SE. Prevalence of musculoskeletal disorders for nurses in hospitals, long-term care facilities, and home health care: a comprehensive review. Hum Factors. 2015;57(5):754-92.

8. Lorusso A, Bruno S, L'Abbate N. A review of low back pain and musculoskeletal disorders among Italian nursing personnel. Ind Health. 2007;45(5):637-44.

9. Moher D, Liberati A, Tetzlaff J, Altman DG. PRISMA group. Preferred reporting items for systematic reviews and meta-analyses: the PRISMA statement. J Clin Epidemiol. 2009;62(10):1006-12.

10. Johanna Briggs Institute. JBI Data Extraction Form for Review for Systematic Reviews and Research Syntheses. 2014.

11. Foroutan F, Guyatt G, Zuk V, Vandvik PO, Alba AC, Mustafa R, et al. GRADE guidelines 28: use of grade for the assessment of evidence about prognostic factors: rating the certainty in the identification of groups of patients with different absolute risks. J Clin Epidemiol. 2020;121:62-70.

12. Higgins JPT, Thompson SG, Deeks JJ, Altman DG. Measuring inconsistency in meta-analyses. BMJ. 2003;327(7414):557-60.

13. Ruzafa-Martinez M. Madrigal de Torres F, Ruiz Garcia MJ, Salinas Marin R. improving the quality of work life. Awkward and strained postures among scrub nurses. Rev ROL enf. 2003;26(4):302-6.

14. Bos E, Krol B, Van Der Star L, Groothoff J. Risk factors and musculoskeletal complaints in non-specialized nurses, IC nurses, operation room nurses, and X-ray technologists. Int Arch Occup Environ Health. 2007;80(3):198-206.

15. Meijsen P, Knibbe HJJ. Work-related musculoskeletal disorders of perioperative personnel in the Netherlands. AORN J. 2007:86(2):193-208.

16. Sheikhzadeh A, Gore C, Zuckerman JD, Nordin M. Perioperating nurses and technicians' perceptions of ergonomic risk factors in the surgical environment. Appl Ergon. 2009:40(5):833-9.

17. Moscato U, Trinca D, Rega ML, Mannocci A, Chiaradia G, Grieco G, et al. Musculoskeletal injuries among operating room nurses: results from a multicenter survey in Rome, Italy. Aust J Public Health. 2010;18(5):453-9.

18. Choobineh A, Movahed M. Perceived demands and musculoskeletal disorders. Ind Health. 2010;48(1):74-84.

19. Aljeesh Yl, Nawajha SA. Determinants of low Back pain among operating room nurses in Gaza governmental hospitals. J Al Azhar Univ Gaza. 2011;13: $41-54$.

20. Hinmikaiye CD, Bamishaiye El. The incidence of low Back pain among theatre nurses : a case study of University of Ilorin and Obafemi Awolowo University Teaching Hospital. Int J Nurs Sci. 2012;2(3):23-8.

21. Keriri HM. Prevalence and risk factors of low back pain among nurses in operating rooms, Taif, Saudi Arabia. Am J Res Commun. 2013;1(11):45-70.

22. Arsalani N, Fallahi-Khoshknab M, Josephson M, Lagerstrom M. Musculoskeletal disorders and working conditions among Iranian nursing personnel. Int J Occup Saf Ergon. 2014;20(4):671-80.

23. Ryu E, Ye B, Yi Y, Kim J. Risk factors of musculoskeletal symptoms in university hospital nurses. Ann Occup Environ Med. 2014;26(1):1-8.

24. Uğurlu Z, Karahan A, Ünlu H, Abbasoglu A, Ozhan Elbas N, Avci Isik S, et al. The effects of workload and working conditions on operating room nurses and technicians. Workplace Health Saf. 2015;63(9):399-407.

25. Nützi M, Koch P, Baur H, Elfering A. Work e Family Conflict, Task Interruptions, and Influence at Work Predict Musculoskeletal Pain in Operating Room Nurses. Saf Health Work. 2015;6(4):329-37.

26. El Ata GA, El Desouky S, Manawil M, Khalifa E. Assessment of work- related musculoskeletal symptoms in operation room nurses. Curr Sci Int. 2016;5(2): 215-22.

27. Arvidsson I, Simonsen JG, Dahlqvist C, Axmon A, Karlson B, Björk J, et al. Cross-sectional associations between occupational factors and musculoskeletal pain in women teachers, nurses and sonographers. BMC Musculoskelet Disord. 2016;17:35. 
28. Asadi P, Kasmaei VM, Mahdi S, Ziabari Z, Zohrevandi B. The prevalence of low back pain among nurses working in Poursina hospital in Rasht, Iran. JEPT. 2015;2(1):11-5.

29. Mahmoudifar $Y$, Seyedamini B. Ergonomic relationship during work in nursing staff of intensive care unit with operating room. Int Arch Health Sci. 2017:4(2):42-7.

30. Bakola H, Zyga S, Stergioulas A, Kipreos G, Panoutsopoulos G. Musculoskeletal problems among Greek perioperative nurses in regional hospitals in southern Peloponnese: musculoskeletal problems in perioperative nurses. Adv Exp Med Biol. 2017;989:21-37.

31. Nasiri-Ziba F, Nosrati S, Hanani S. The prevalence of musculoskeletal disorders among undergraduates and technicians of operating room of the educational hospitals affiliated with Iran University of Medical Sciences in 2016. Nurs Pract Today. 2017;4(3):134-42.

32. Simonsen JG, Arvidsson I, Nordander C. Ergonomics in the operating room. Work. 2012;41:5644-6.

33. Clari M, Garzaro G, Di Maso M, Donato F, Godono A, Paleologo M, et al. Upper limb work-related musculoskeletal disorders in operating room nurses: a multicenter cross-sectional study. Int J Environ Res Public Health. 2019;16(16):28-44.

34. Jeyakumar AK, Segaran F. Prevalence and risk factors of low back pain and disability index among operating room nurses. J Perioperative Nurs. 2018; 31(3):21-4.

35. Homaid MB, Abdelmoety D, Alshareef W, Alghamdi A, Alhozali F, Alfahmi N, et al. Prevalence and risk factors of low back pain among operation room staff at a tertiary care center, Makkah, Saudi Arabia: a cross-sectional study. Ann Occup Environ Med. 2016;28:1

36. Asghari E, Dianat I, Abdollahzadeh F, Mohammadi F, Asghari P, Jafarabadi MA, et al. Musculoskeletal pain in operating room nurses: associations with quality of work life, working posture, socio-demographic and job characteristics. Int J Ind Ergon. 2019;72:330-7.

37. Global Burden Disease 2017 Disease and Injury Incidence and Prevalence Collaborators. Global, regional, and national incidence, prevalence, and years lived with disability for 354 diseases and injuries for 195 countries and territories, 1990-2017: a systematic analysis for the Global Burden of Disease Study 2017. Lancet. 2018:1990-2017.

38. World Health Organization. Musculoskeletal conditions. 2019. https://www. who.int/news-room/fact-sheets/detail/musculoskeletal-conditions. Accessed 02 Dec 2020.

39. Dong H, Zhang Q, Liu G, Shao T, Xu Y. Prevalence and associated factors of musculoskeletal disorders among Chinese healthcare professionals working in tertiary hospitals : a cross-sectional study. BMC Musculoskelet Disord. 2019:5(45):1-7.

40. Cheung K. Prevalence of and factors associated with work-related musculoskeletal symptoms in nursing assistants working in nursing homes. Int J Environ Res Public Health. 2018;15(2):265.

41. Epstein S, Sparer EH, Tran BN, Ruan QZ, Dennerlein JT, Singhal D, et al. Prevalence of work-related musculoskeletal disorders among surgeons and prevalence of work-related musculoskeletal disorders among surgeons and Interventionalists a systematic review and Meta-analysis. JAMA Surg. 2017; 153(2):e174947.

42. Wieser S, Horisberger B, Schmidhauser S, Eisenring C. Cost of low back pain in Switzerland in 2005. Eur J Health Econ. 2011;12(5):455-67.

43. Shemshaki $H$, Nourian MA, Fereidan-esfahani M, Etemadifar M. What is the source of low back pain? JCVJS. 2013;4(1):21-4

44. Yassi A, Lockhart L. Work-relatedness of low back pain in nursing personnel: a systematic review. Int J Occup Environ Health. 2013;19(3):223-44.

45. Kant IJ, de Jong LC, van Rijssen-Moll M, Borm PJ. A survey of static and dynamic work postures of operating room staff. Int Arch Occup Environ Health. 1992;63(6):423-8.

46. Hughes NL, Nelson A. Solutions for prolonged standing in perioperative settings. AORN J. 2011;93(6):767-74

47. Liuke M, Solovieva S, Lamminen A, Luoma K, Leino-Arjas P, Luukkonen R, et al. Disc degeneration of the lumbar spine in relation to overweight. Int J Obes. 2005;29(8):903-8

48. Sikiru L, Shmaila H. Prevalence And Risk Factors Of Low Back Pain Among Nurses In Africa: Nigerian And Ethiopian Specialized Hospitals Survey Study. East Afr J Public Health. 2009;6(1):22-5.

49. Sormunen E, Rissanen S, Oksa J, Pienimäki T, Remes J, Rintamäki H. Muscular activity and thermal responses in men and women during repetitive work in cold environments. Ergonomics. 2009;52(8):964-76.
50. Van Der Beek AJ, Kluver BDR, Frings-Dresen MHW, Hoozemans MJM. Sex differences in exerted forces and physiological load during pushing and pulling of wheeled cages by postal workers. Ergonomics. 2000;43(2):269-81.

51. Strazdins L, Bammer G. Women, work and musculoskeletal health. Soc Sci Med. 2004;58(6):997-1005.

52. Kanter R, Caballero B. Global sex disparities in obesity: a review. Adv Nutr. 2012;3(4):491-8.

53. Côté JN. A critical review on physical factors and functional characteristics that may explain a sex/gender difference in work-related neck/shoulder disorders. Ergonomics. 2012;55(2):173-82.

54. van Dam RM, Willett WC, Manson JE, Hu FB. The relationship between overweight in adolescence and premature death in women. Ann Intern Med. 2006;145(2):91.

55. Miranda H, Viikari-Juntura E, Martikainen R, Takala E-P, Riihimaki H. Physical exercise and musculoskeletal pain among forest industry workers. Scand J Med Sci Sports. 2001;11(4):239-46.

56. Tunceli K, Li K, Williams LK. Long-term effects of obesity on employment and work limitations among U.S. adults, 1986 to 1999. Obesity. 2006;14(9): 1637-46.

57. Letvak $\mathrm{S}$. The experience of being an older perioperative nurse. AORN J. 2003;78(4):635-49.

58. Okunribido OO, Wynn T, Lewis D. Are older workers at greater risk of musculoskeletal disorders in the workplace than young workers? - A literature review. Occup Ergon. 2011;10(1,2):53-68.

59. Buerhaus PI, Auerbach DI, Staiger DO, Muench U. Projections of the longterm growth of the registered nurse workforce: a regional analysis. Nurs Econ. 2013;31(1):13-7.

60. Canadian Centre for Occupational Health \& Safety. Working in a standing position - basic information. 2016. https://www.ccohs.ca/oshanswers/ ergonomics/standing/standing_basic.html. Accessed 02 Dec 2020.

61. Baracco A, Coggiola M, Bosio D, Perrelli F, Garzaro G, Turcu V, et al. Whole body biomechanical burden of healthcare workers: proposal for a complementary risk assessment and management tool (HOARA). Med Lav. 2019;110(5):372-88.

\section{Publisher's Note}

Springer Nature remains neutral with regard to jurisdictional claims in published maps and institutional affiliations.
Ready to submit your research? Choose BMC and benefit from:

- fast, convenient online submission

- thorough peer review by experienced researchers in your field

- rapid publication on acceptance

- support for research data, including large and complex data types

- gold Open Access which fosters wider collaboration and increased citations

- maximum visibility for your research: over $100 \mathrm{M}$ website views per year

At $\mathrm{BMC}$, research is always in progress.

Learn more biomedcentral.com/submissions 